\title{
Glial Cyst inside the Cerebellar Parenchyma: Case Report and Literature Review
}

\section{Cisto glial no parênquima cerebelar: relato de caso e revisão da literatura}

\author{
Guilherme Finger ${ }^{1} \quad$ Eduardo Cambruzzi $^{2}$ Tobias Ludwig do Nascimento ${ }^{1}$ \\ Luiz Pedro Willimann Rogerio ${ }^{1}$ Marcelo Martins dos Reis ${ }^{1}$ Leandro Pelegrini de Almeida ${ }^{1}$ \\ Gabriel Greggianin Frizzon ${ }^{1}$ Pasquale Gallo ${ }^{1}$
}

${ }^{1}$ Department of Neurosurgery, Hospital Cristo Redentor, Porto Alegre, Rio Grande do Sul, Brazil

2 Department of Pathology, Hospital Cristo Redentor, Porto Alegre,

Address for correspondence Guilherme Finger, MD, Departmento de Neurocirurgia, Hospital Cristo Redentor, Porto Alegre, Rio Grande do Rio Grande do Sul, Brazil Sul, Brazil (e-mail: guilhermefingermd@gmail.com).

Arq Bras Neurocir 2016;35:329-333.

\begin{abstract}
Cystic lesions inside the brain parenchyma are a common pathological finding in the investigation of patients with suspicion of cerebral tumor. Histological diagnosis is important to guide the patient's treatment and follow-up, and to determine prognosis.

Keywords

- cerebellar cyst

- cysts inside the parenchyma

- glial cyst

Resumo

Palavras-chave

- cisto cerebelar

- cisto intraparenquimatoso

- cisto glial Among patients diagnosed with cerebral cysts, most are located in the parenchyma above the tentorium. The authors describe the case of a patient who had been suffering from dizziness and balance disturbance for 4 months; the investigation identified a cyst inside the cerebellar right hemisphere. A surgical procedure was performed, and the biopsy microscopic analysis diagnosis was glial cyst.

Patologias intraparenquimatosas de características císticas são comumente identificadas em pacientes que estão sob investigação de neoplasias cranianas. Lesões císticas são mais prevalentes acima da tenda cerebelar, e o diagnóstico histológico é fundamental para determinar o tratamento, seguimento e prognóstico do paciente. Os autores relatam o caso de um paciente com sintomas de vertigem e alteração no equilíbrio dinämico de 4 meses de evolução, cuja investigação diagnosticou cisto intraparenquimatoso no hemisfério cerebelar direito. Procedeu-se com intervenção cirúrgica cujo diagnóstico histopatológico foi compatível com Cisto Glial
\end{abstract}

\section{Introduction}

\section{Case Report}

A 63 year-old retired man was admitted to the neurosurgical department of Hospital Cristo Redentor (located in the city of Porto Alegre, Brazil) with a history of whole brain headache associated with vertigo and loss of balance for the four months previous to the medical evaluation. The patient had no history of head trauma or oncologic records. The neurological exam did not evidence sensitive or motor deficits, no deep or superficial reflex asymmetry, and cranial nerve tests did not evidence any impairment. Muscular tonus and tropism were normal. Cerebellar tests did not show any alteration. Although the patient did not stand still when he received

April 13, 2016

accepted

July 11, 2016

published online

August 12, 2016
DOI http://dx.doi.org/

10.1055/s-0036-1586760. ISSN 0103-5355.
Copyright (e 2016 by Thieme-Revinter

Publicações Ltda, Rio de Janeiro, Brazil
License terms

(ㄷ) (i) $\ominus$ (5) 


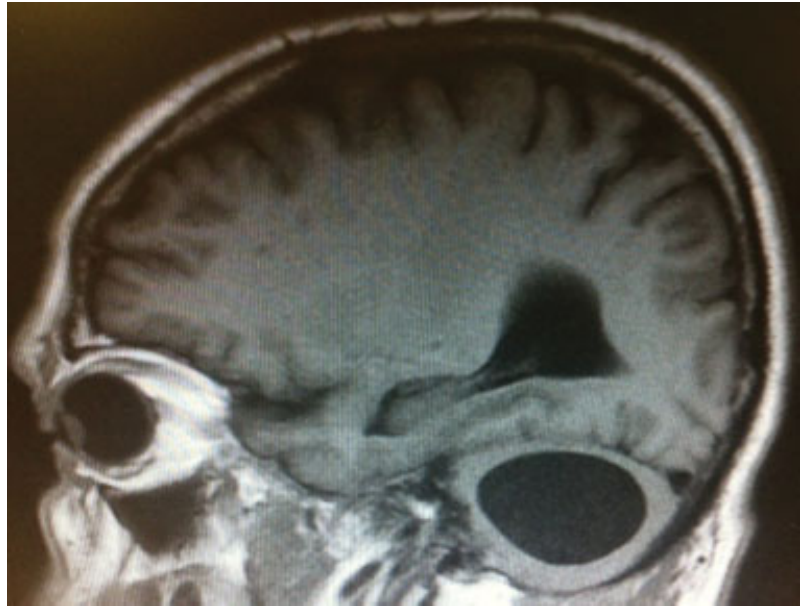

Fig. 1 Magnetic Resonance in the T1 weight series on sagittal view showing a cyst inside the cerebellar parenchyma. was asked to stand up and close his eyes, he did not fall. Dynamic balance was deviated to the left, a sign that was clearer when the patient tried to walk with one foot right in front of the other following a straight line drawn on the floor. The patient had no vertigo associated with fast passive head rotation, but his thought and speech was slow.

A computed tomography (CT) scan was performed, and it showed a hypodense and cystic lesion in the right cerebellar hemisphere, with no apparent solid tissue around or inside its borders. To better analyze the lesion and try to limit diagnoses options, full magnetic resonance imaging (MRI) was performed. The exam showed a cystic intracerebellar lesion, with a hypointense sign on the T1 series ( - Fig. 1) and a hyperintense sign on the T2 series (-Fig. 2), but without contrast sign after a gadolinium infusion (-Fig. $\mathbf{3}$ ). The MRI also evidenced that the lesion did not have contact with the subarachnoid space or with the fourth ventricle. No artery or venous blood vessels were related to the cyst, and there was no solid tumor or apparent capsule surrounding it. Although the cyst did not have communication with the cisternal or

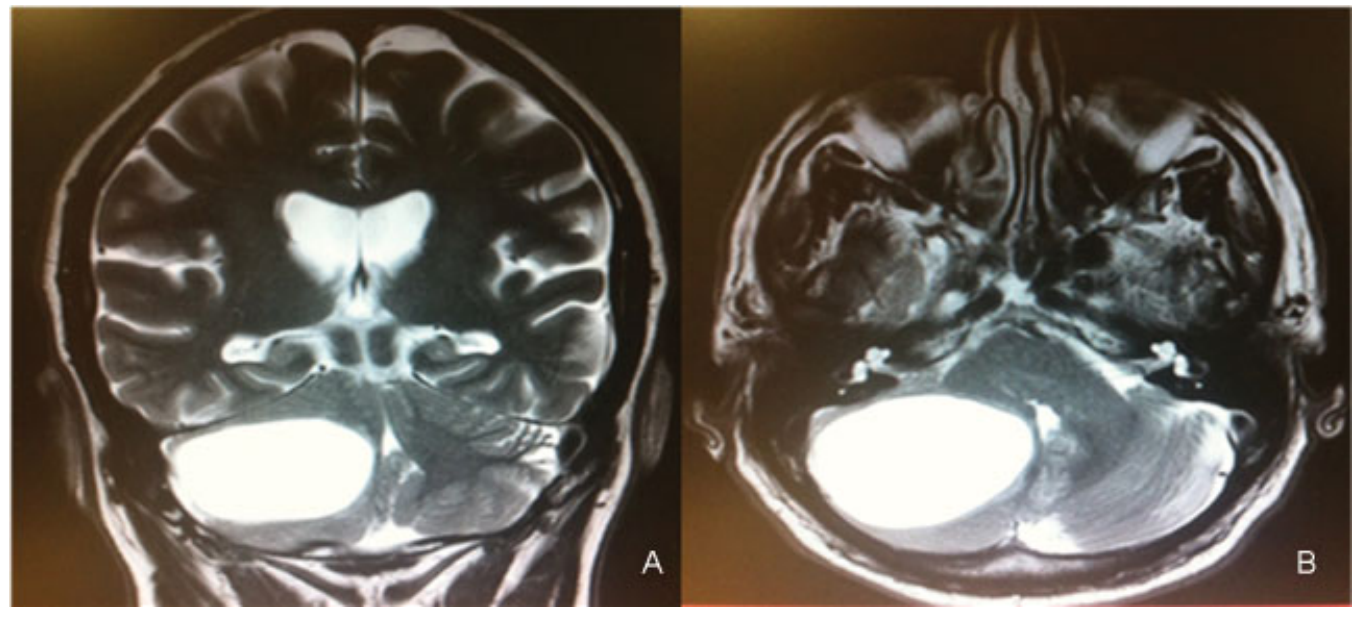

Fig. 2 Magnetic resonance in the T2 weight series on coronal (A) and axial (B) views. Both images show a cystic lesion with intensity similar to the cerebrospinal fluid's. A fourth ventricle deviation to the left side is also shown in both images.

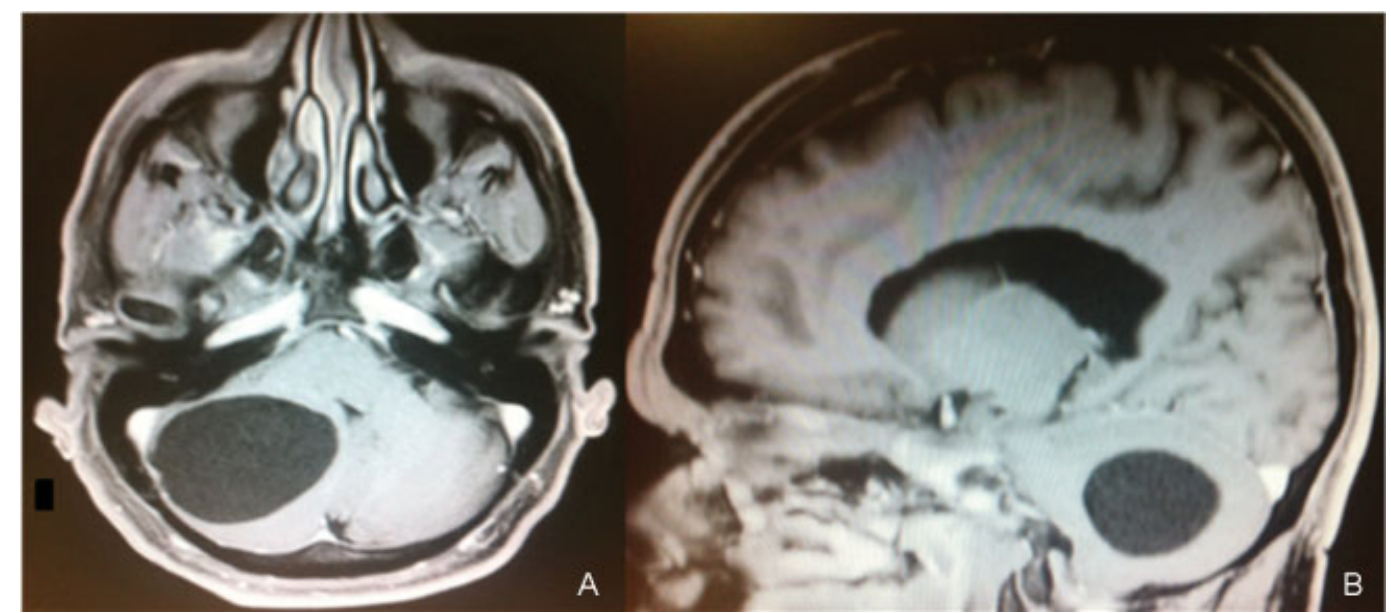

Fig. 3 Magnetic resonance images in axial (A) and sagittal (B) views in the T1 series after a gadolinium infusion. In both images there is no contrast enhancement inside the cyst or its borders. 
ventricular systems, the intensity of its content was similar to the liquor's. The fourth ventricle was compressed and deviated to the left side. However, the patient had no clinical or radiological criteria for hydrocephalus.

The patient was then submitted to surgery to analyze the cyst's content and pathological diagnosis. A lateral suboccipital access was performed, exposing the cerebellar right hemisphere. Once the surgical site was reached, a tan-yellow fluid was aspirated, without signs of recent or old hemorrhages. A macroscopic inspection showed a regular parenchyma, and this impression was maintained during the microscopic view. The cystic walls were opaque with regular cerebellar tissue appearance, and no solid tissue was found during inspection. Neurosurgeons decided to perform random biopsies of the cyst wall, drain its fluid content, and send it to pathology and microbiology analyses.

The patient's surgical recovery was excellent: he had no more headaches, could walk by himself without balance disturbance, and his speed of thought and speech improved. A CT scan after surgery showed a satisfactory cyst reduction (-Fig. 4).

Laboratory results evidenced a basic fluid $(\mathrm{pH}$ value of 8.56 ) with lactate of $2,8 \mathrm{mg} / \mathrm{dL}$, elevated protein concentration $(2000 \mathrm{mg} / \mathrm{dL})$ and normal glucose value $(60 \mathrm{mg} / \mathrm{dL})$. Microbiological investigation did not found any bacteria, fungus or bacillus tuberculosis on cultural exams. Cytopathological analyses demonstrated a liquid with rare epithelioid cells with no atypical nuclear and cellular structures. The histopathological microscopic structure evidenced three layers of regular glial cells surrounding the cyst, with a diagnosis of glial cyst (-Fig. 5).

The patient was released from the hospital one week after surgery, without neurological impairments, a clinical status that remained the same during follow-up. However, a CT scan performed three months after surgery showed a reorganiza-

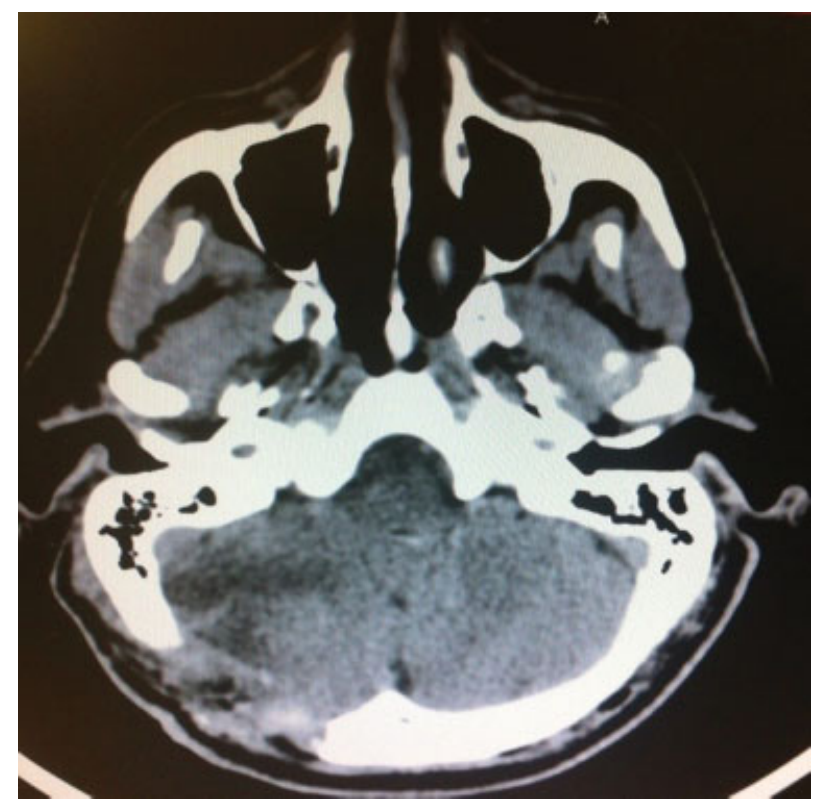

Fig. 4 Computed tomography scan after surgery showing lesion removal.
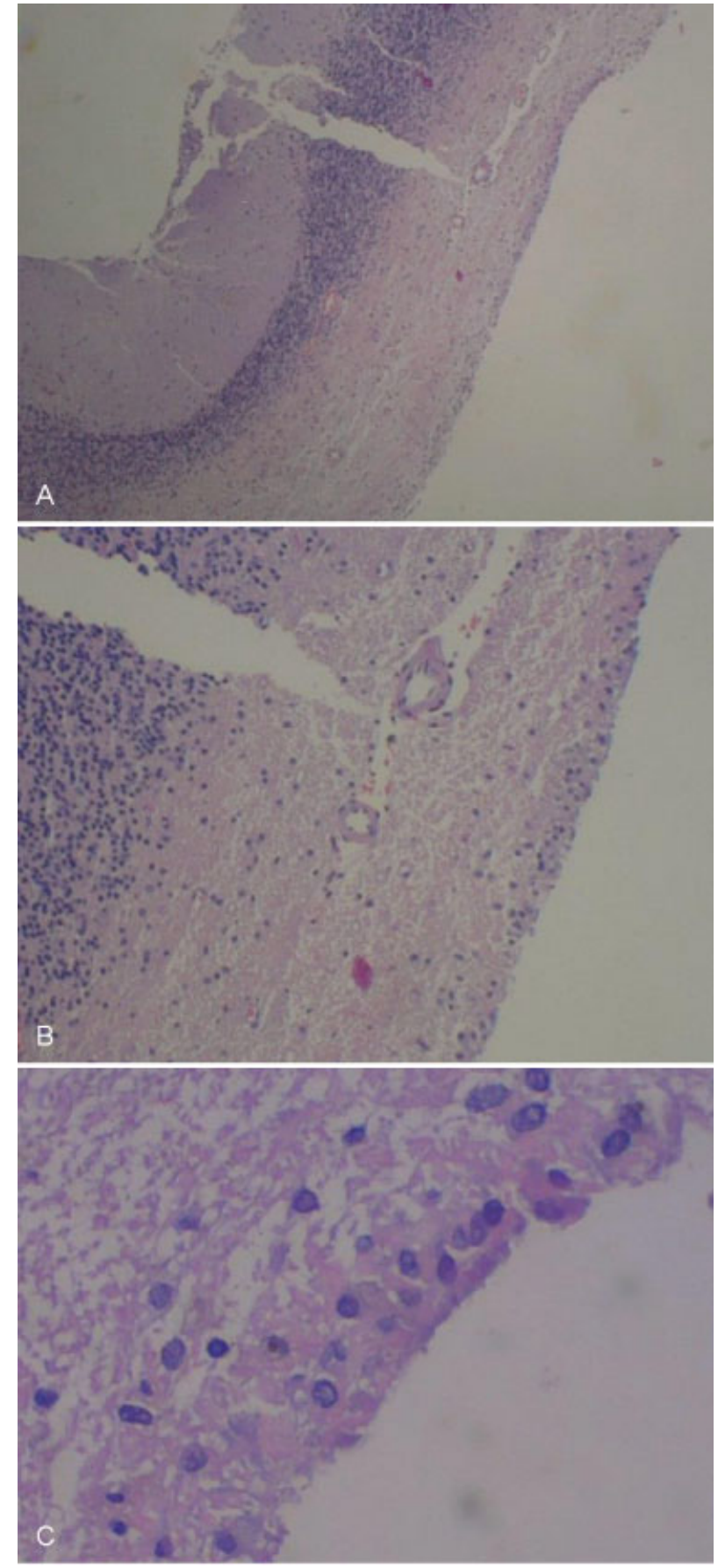

Fig. 5 Histopathological microscopic view in three augments (A, 10x; $B, 100 x$; and C, 1000x). All images show a three-layer structure of regular glial cells surrounding the cyst.

tion, in smaller proportions, of a cystic lesion in the same anatomical place ( - Fig. $\mathbf{6}$ ). Since the patient was asymptomatic and the histological diagnosis of a benign pathology was known, the authors decided to follow this patient with CT scans and neurological evaluations every six months.

\section{Discussion}

Posterior fossa cysts located inside the parenchyma can be classified into neoplasm or non-neoplasm types. Pilocytic 


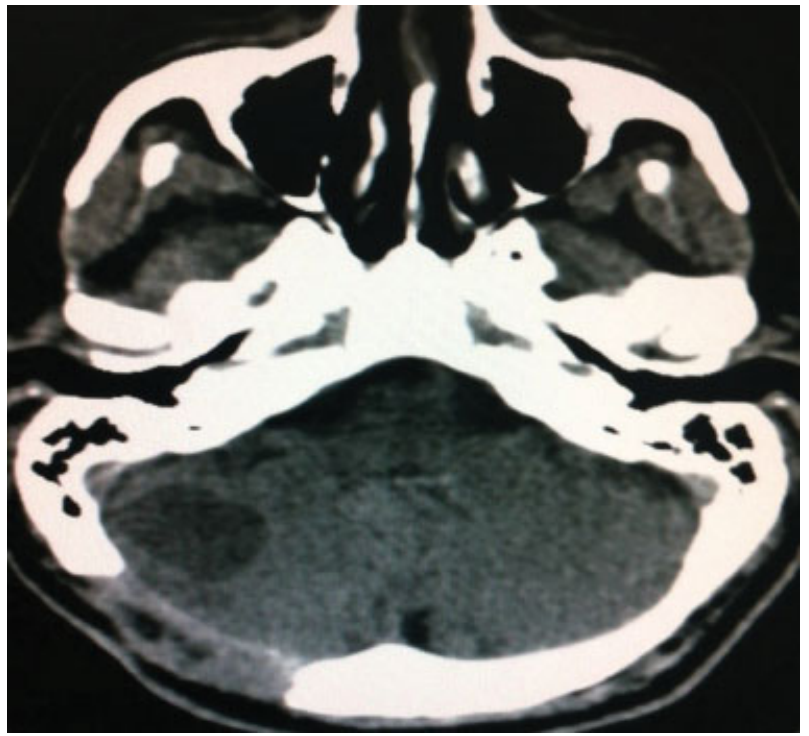

Fig. 6 Brain computed tomography performed in the third month of follow-up after surgery. There is a hypodense image corresponding to a small cyst in the right cerebellar hemisphere.

astrocytomas, cystic teratomas, hemangioblastomas, metastases and ependymomas should be included in the differential list of the former type. ${ }^{1}$ The differential diagnosis of nonneoplasm posterior fossa cystic lesions includes many entities, such as infectious pathologies (toxoplasma abscesses, neurocysticercosis or hydatid cysts), arachnoid cyst, colloid, epidermoid or dermoid cysts. ${ }^{2}$ A least common differential diagnosis is the glial cyst, a very rare entity encountered in adults or older patients.

An article published in 1982 found 14 cases described in the medical literature from 1926 and $1981{ }^{3}$ A recent study conducted by Sundaram et al in 2001 analyzed 145 patients with diagnoses of cyst in the central nervous system across 12 years. Among these 145 cases, 2 (1,37\%) were glial cysts, and both were located inside the cerebellar parenchyma. ${ }^{4}$

Cysts of the central nervous system are usually benign and secondary to neural development defects. A few are acquired, secondary to processes such as hemorrhage, infarction, infection, trauma, or surgery. ${ }^{4,5}$

Specific explanations about the origin, etiology and pathogenesis of intracerebellar glial cysts are not clear and are difficult to determine. Analyses of all cases described in the medical literature allow authors to rule out vascular or degenerative diseases, infections and trauma as pathogenic factors. ${ }^{6}$

The proximity of the cyst to the fourth ventricle in the two cases reported by Vaquero et al made the authors hypothesize that the cyst originated from an ependymal diverticulum during intrauterine development, an idea first proposed by Szigethy. ${ }^{6,7}$ Some authors believe that they are probably formed by budding from the ventricular system, like an ependymal cyst with subsequent loss of ependymal cells by stretching or pressure effects. ${ }^{8}$ However, other authors accept as more plausible the hypothesis that a simple glial cyst represents an aborted or degenerated cerebellar astro- cytoma, especially because of the fact that the reported glial cysts of the cerebellum are usually diagnosed during the fourth and fifth decades of life, allowing the assumption of degenerative changes in a previous undiagnosed cerebellar astrocytoma. $^{6,9}$

Most cases are asymptomatic, and the diagnosis occurs incidentally during imaging exams. However, they may become symptomatic because of pressure, rupture, or a secondary inflammation. ${ }^{4}$ Among the symptomatic cases, symptoms of increased intracranial pressure secondary to the cyst itself or obstruction of the fourth ventricle are the most common clinical manifestations. ${ }^{1}$ Both cases described by Vaquero et al presented a clinical evolution of a slowly growing expansive lesion. ${ }^{6}$ In our case, the cystic growth compressed the fourth ventricle, which impaired cerebrospinal fluid flow, causing the symptoms of headache and bradipsychism.

The first CT findings of cerebellar glial cysts were published in $1981 .^{6}$ The cyst usually is homogeneously hypodense, with a Hounsfield count similar to the cerebrospinal fluid's. An important characteristic is that glial cysts are not vascularized, and, therefore, do not enhance after contrast injection. ${ }^{10}$ On MRI, the cystic lesions have a signal characteristic of cerebrospinal fluid, ${ }^{10}$ a pattern showed during the radiological investigation of the case here described.

Despite the well-established characteristics on image exams, neuroradiological analysis without histological verification does not predict the benign nature of the lesion. A histopathologic study is important for diagnosis, to guide therapy and to establish patient prognosis. ${ }^{11}$ Therefore, special attention must be paid to obtaining adequate surgical specimens in order to distinguish a glial cyst from a more aggressive pathology, such as low-grade neoplasm.

On macroscopic inspection, the cyst is tan-yellow or opaque, and has a smooth capsule that may be up to $2 \mathrm{~mm}$ thick. The fluid content is clear yellow or yellow-white (from elevated protein content), and is not xanthochromic. ${ }^{3}$ These cysts may be unilocular or multilocular, with a central or lateral location, typically confined to the white matter, but they may also affect gray matter. ${ }^{12}$

Microscopically, the appearance of the cyst wall is characteristic, revealing the cyst surrounded by bands of fibrous glial tissue. The wall is composed of three layers of neurologic structure with no epithelial lining. The outer layer consists of a fibrous capsule. The fibroblasts are sometimes arranged in a thin layer, but are more commonly densely packed. The inner layer is formed by a thin lining of glial cells. No mural nodules, tumor cells, or evidence of old or recent hemorrhages can be detected. ${ }^{3,10,11}$

During surgery, once the cyst is reached, the surgeon must carefully look around the cystic cavity to try to identify a nodular or solid area to guide surgical biopsy. Characteristically, no signs of tumor nodules are found, and the surgeon must perform random biopsies of the cystic wall for pathological analyses. Once the pathological diagnosis of glial cyst is confirmed, surgical excision (if not performed during the first surgery) must be performed and is curative. 
The radiological recognition of these cysts and diagnosis confirmation by pathology is essential for prognosis, which is extremely good once surgical evacuation of the cyst is performed. $^{6}$

\section{Conclusion}

In a late middle-aged patient with appropriate cerebellar signs, a neuroradiological demonstration of a well-defined, non-enhancing cystic lesion on CT and MRI scans makes the diagnosis of a simple cerebellar cyst probable. However, the neurosurgeon must always exclude tumor and infectious pathologies, once they have a different prognosis and specific treatments. Besides, any tumoral growth in the posterior fossae may obstruct or divert the fourth ventricle, causing hydrocephalus and increasing intracranial pressure. In these cases, surgical resection is indicated.

\section{References}

1 Frazier J, Garonzik I, Tihan T, Olivi A. Recurrent glioependymal cyst of the posterior fossa: an unusual entity containing mixed glial elements. Case report. J Neurooncol 2004;68(1): $13-17$
2 Oprişan A, Popescu BO. Intracranial cysts: an imagery diagnostic challenge. Scientific World Journal 2013;2013:172154

3 Weisberg LA. Non-neoplastic gliotic cerebellar cysts: clinical and computed tomographic correlations. Neuroradiology 1982;24(1): 53-57

4 Sundaram C, Paul TR, Raju BV, et al. Cysts of the central nervous system : a clinicopathologic study of 145 cases. Neurol India 2001; 49(3):237-242

5 Lustgarten L, Papanastassiou V, McDonald B, Kerr RS. Benign intracerebral cysts with ependymal lining: pathological and radiological features. Br J Neurosurg 1997;11(5):393-397

6 Vaquero J, Cabezudo JM, Areitio E. Glial cysts of the cerebellum. Surg Neurol 1981;16(4):288-289

7 Szigethy A. Beitrage zur Genese der Kleinhirncystern. Arch Psychiatr. 1928;84:715-725

8 Wilkins RH, Burger PC. Benign intraparenchymal brain cysts without an epithelial lining. J Neurosurg 1988;68(3):378-382

9 Silverberg GD. Simple cysts of the cerebellum. J Neurosurg 1971; 35(3):320-327

10 Klein P, Rubinstein LJ. Benign symptomatic glial cysts of the pineal gland: a report of seven cases and review of the literature.J Neurol Neurosurg Psychiatry 1989;52(8):991-995

11 Taraszewska A, Matyja E, Koszewski W, Zaczyński A, Bardadin K, Czernicki Z. Asymptomatic and symptomatic glial cysts of the pineal gland. Folia Neuropathol 2008;46(3):186-195

12 Sundbärg G, Brun A, Efsing HO, Lundberg N. Non-neoplastic expanding lesions of the vermis cerebelli. J Neurosurg 1972; 37(1):55-64 